\title{
The Cultural Impact of Chinese Students' Self-Construals on Communication Competence
}

\author{
Gang Zhou*, Xiaochun Niu \\ School of Foreign Languages, Dalian University of Technology, Dalian City, China
}

*Corresponding Author: Gang Zhou, School of Foreign Languages, Dalian University of Technology, Dalian City, China

\begin{abstract}
The purpose of the study sets out to address issues such as whether the mainland Chinese students better develop interdependent self-construals than the Chinese sojourners, and to what extent a Western cultural context affects the Chinese sojourners' perceptions of self-construals on interdependence and independence. This research compares a sample of 40 mainland Chinese students and a sample of 20 Chinese sojourners studying in Wales. The respondents were asked to complete a structured self-completion questionnaire. The findings seem to suggest that culture teaches one how to think, conditions one how to feel, and instructs one how to act, especially how to interact with others. It concludes that both the mainland Chinese students and the Chinese sojourners have well developed interdependent self construals and independent self construals. It is also suggested that the traditional cultural values brought with the Chinese sojourners have been well preserved in a Western cultural context.
\end{abstract}

Keywords: Self-Construal, Communication Competence, Interdependence and Independence

\section{INTRODUCTION}

The importance of communication competence is recognized universally by philosophers and scientists of human interaction and has been extensively researched in the West, especially in the US (Spitzberg and Cupach, 1984; Spitzberg and Cupach, 1989). Due to the rapid development of communication technologies, the world is becoming smaller and smaller and various cultures are surging ahead in this "global village" (Guan, 1998). Due to the growing international economic and intercultural exchanges, multicultural and multiethnic interactions and "clashes" are unavoidable. As a result, researchers and scientists of human interaction are being motivated to develop the human aspects such as knowledge and communication skills (Chua, 2003). In order to cohabit in the "global village", to achieve effective interpersonal communication, people have to acquire the necessary knowledge and skills (as indicators of communication competence defined by Hammer, 1989), the "human aspects", so that they can better understand, empathize, collaborate and interact among people from within and between cultures (Miyahara, 1998).

Although numerous studies have been conducted on communication both from cultural and crosscultural perspectives, most analyses of communication, however, ignore the relationship that "communication and culture reciprocally influence each other. The culture in which individuals are socialized influences the way they communicate, and the way that individuals communicate can change the culture they share over time" (Gudykunst, 1997, p: 327).

It is this gap in the relationship between communication and culture that the researcher expects to focus on in this study. This research investigates in what ways the Chinese traditional values (defined as cultural self-construal) influence Chinese students' perceptions of communication competence and style. In addition, a sample of Chinese sojourners in Wales is compared to a sample of mainland Chinese undergraduates. This will provide information on the possible influence of Western cultural context on Chinese students. In general, it is intended to gain an insight into cultural impact on Chinese students' self construals on communication competence in the traditional cultural context and a Western cultural context.

The main purpose of the study sets out to address issues such as whether the mainland Chinese students better develop interdependent self-construals than the Chinese sojourners, but may be similar 
to the Chinese sojourners in the development of their independent self-construals, and to what extent a Western cultural context affects the Chinese sojourners' perceptions of self-construals on interdependence (collectivistic) and independence (individualistic). The study also sets out to address the issue such as whether the traditional cultural values brought with the Chinese sojourners are well preserved while the dimensions of independence in them are well developed due to the influence of a Western cultural context in which they are socialized.

\subsection{Definition of Communication Competence}

Hewstone et al. (1988) defines communication as message exchange between two or more participants which is characterized by the intentional, conscious (at some level of awareness) use of mutually intelligible symbol systems. Sarbaugh (1988) prefers to define communication as the process of using signs and symbols that elicit meanings in another person or persons for whatever intent, or even without conscious intent, on the part of the person producing the symbols or signs.

Hammer (1989: 247) points out that "communication competence has been examined by scholars from a variety of academic disciplines under such diverse linguistic umbrellas as interpersonal effectiveness, social competence, fundamental competence, rhetorical competence, and linguistic competence". Hammer believes that these five communication skills more or less influence people's communication behaviours. van Ek's model of "communicative ability" (1986) comprises six competences - linguistic competence, sociolinguistic competence, discourse competence, strategic competence, socio-cultural competence and social competence. Wiemann (1977: 195-213) proposes a model of competence with five components - empathy, affiliation/support, social relaxation, behavioral flexibility, interaction management. In his model, communicative competence is defined as "the ability of an interactant to choose among available communicative behaviours in order that he [she] may successfully accomplish his [her] own interpersonal goals ... while maintaining the face and line of his [her] fellow interactancts within the constraints of the situation".

According to Lustig and Koester (1999), although there is still some disagreement among communication scholars about how best to conceptualize and measure communication competence, there is increasing agreement about certain of its fundamental characteristics. The following definition of communication competence illustrates the key components of their approach: Competent communication is interaction that is perceived as effective in fulfilling certain rewarding objectives in a way that is also appropriate to the context in which the interaction occurs.

Communication competence involves interactants making social judgments concerning the "goodness" of self and others' communicative performances (Spitzberg \& Coupach, 1984). According to Spitzberg and Cupach (1989), both appropriateness and effectiveness are dimensions that people use to base their judgments of a communicative performance. To elaborate on this point, an individual is considered competent if he or she is capable of successful communication in an effective and appropriate manner. Spitzberg and Cupach (1989: 7) contend that "Effectiveness derives from control and is defined as successful goal achievement or task accomplishment. ... Appropriateness reflects tact or politeness and is defined as the avoidance of violating social or interpersonal norms, rules, or expectations."

\subsection{Interdependent and Independent Self-Construals}

Gudykunst (1997) has identified three individual-level factors that mediate the influence of culturallevel. They are values, personality orientations and self construals. In this section, self construals are focused and explicated.

The prototypical view of self in North American and Asian cultures varies markedly (Singelis, 1994). Markus and Kitayama (1991) have delineated these two views of the self in relation to the collective. They propose that people in the West hold an independent view of the self that emphasizes the separateness, internal attributes, and uniqueness of individuals (the independent self-construal) and that many non-Western peoples hold an interdependent image of self stressing connectedness, social context, and relationships (the interdependent self-construal). Singelis (1994) contends that like independent and interdependent self-construals (individual difference variables), individualismcollectivism (a cultural variable) is concerned with the relationship of the individual to the collective. The central meaning of individualism is giving priority to personal goals over in-group goals. Collectivism places an emphasis on subordinating personal goals to those of the in-group (Triandis, 
1988). According to Markus and Kitayama (1991), individualism has been associated with most northern and western regions of Europe, North America (especially the United States), and Australia. Cultures in Asia, Africa, South America, and the Pacific islands region have been identified as collective. These are respectively the same regions where independent and interdependent selfconstruals are prototypical views of self.

The independent construal of self takes the view that an individual's self is a unique, independent entity (Markus \& Kitayama, 1991). Having the goal of independence "requires construing oneself as an individual whose behaviour is organized and made meaningful primarily by reference to one's own internal repertoire of thoughts, feelings, and actions, rather than by reference to the thoughts, feelings, and actions of others" (p: 226). The important tasks for people emphasizing an independent selfconstrual are to be unique, strive for their own goals, express themselves, and to be direct. Those with well-developed independent self-construals will gain self-esteem through expressing the self and validating their internal attributes. The independent self tends to express itself directly, to say what it thinks. It is one's inner attributes that are most salient for the independent self-construal in "regulating behavior and that are assumed, both by the actor and by the observer alike, to be diagnostic of the actor" (Markus and Kitayama, 1991, p. 227). An interdependent self-construal is defined as a "flexible, variable" self that emphasizes (a) external, public features such as statuses, roles, and relationships, (b) belonging and fitting in, (c) occupying one's proper place and engaging in appropriate action, and (d) being indirect in communication and "reading others' minds" (Markus \& Kitayama, 1991). As Gudykunst (1997) contends that the important tasks for people emphasizing an interdependent self-construal are to fit in with the ingroup, act in an appropriate fashion, promote the ingroup's goals, occupy their proper place, to be indirect, and read other people's minds. Those with highly developed interdependent self-construals think about themselves or others, there is a sense that the self and others are intertwined. Harmonious interpersonal relationships and the ability to adjust to various situations are sources of self-esteem for the interdependent self-constural (Markus \& Kitayama, 1991). Therefore, the interdependent self-construal tends to communicate indirectly and to be attentive to others' feelings and unexpressed thoughts - that is, to "read others' minds." In contrast to the independent self, the interdependent self depends on others, his or her relations with others, and contextual factors to regulate behaviours. Markus and Kitayama have posited that these two types of self are exemplified in Asian (collective) and Western (individualist) cultures. But Singelis (1994) argues that it is proposed that individuals (in any culture) have both independent and interdependent self-construals. However, the more collectivistic an individual's culture is, the stronger his or her interdependent self-construals and the weaker his or her independent self-construals.

Given the ontological difference between individuals with independent and interdependent selfconstruals, the meanings and values that people attach to what appears to be the same communication behaviour greatly vary.

\section{Methodology}

\subsection{Research Questions}

As outlined in the introduction, this research is generally concerned with the cultural impact on Chinese students' self-construals on interdependence and independence. To summarize, given the arguments presented in the literature review and the basic aim in the introduction stem several research questions:

RQ1. What is the relationship between perceptions of oneself as interdependent vs. independent (cultural self construals) and perceptions of communication competence?

RQ2. Does education in a Western context influence Chinese sojourners' perceptions of self and communication competence?

RQ3. Do sojourners' perceptions of self and communication competence differ from mainland Chinese students?

\subsection{Participants}

The most convenient cultural informants were university students (Babbie, 1995), as collaborators in this study were all Chinese students studying in universities to serve this research purpose. The 
procedure was to collect responses from 60 participants from any class level, but from as wide a range of majors as possible. The subjects were 60 Chinese students chosen from two universities' population. One sample of the mainland Chinese students $(N=40)$ was randomly selected from Dalian University of Technology, who were all undergraduate students, and the other sample of Chinese sojourners $(N=20)$ was selected from Cardiff University in Wales, who were all graduate students.

Biographical data gathered from the questionnaire revealed that the average age of the two overall samples $(N=59$; one missing) was 22.75 years $(S D=4.63)$, the youngest was 18 years and the eldest was 41 years (See Table 1); 50\% $(n=30)$ of whom were women, and 50\% $(n=30)$ of whom were men. In addition, 58.3\% $(n=35)$ of the total respondents' majors were Natural Science \& Engineering, and $40.7 \% \quad(n=24)$ of whom were Liberal Arts \& Social Science; $53.3 \%(n=32)$ were either firstyear undergraduates or first-year graduates, 30\% $(n=18)$ were second-year undergraduates, and $16.7 \%(n=10)$ were third-year undergraduates. In the two samples, 50\% $(n=30)$ of whom were the only child in their families with one missing $(S D=0.50)$, and $48.3 \%(n=29)$ were not.

Gang Zhou, Xiaochun Niu

Table1. Descriptive Data for Overall Respondent Background Information

\begin{tabular}{|l|l|l|l|l|}
\hline & \multicolumn{1}{|c|}{ Age } & \multicolumn{1}{c|}{ Gender } & \multicolumn{1}{c|}{ Major } & \multicolumn{1}{c|}{ Year in this degree } \\
\hline Youngest & 18 & $30(\mathrm{M})$ & $35 \mathrm{NSE}^{*}$ & $32($ Year 1)** \\
\hline Eldest & 41 & $30(\mathrm{~F})$ & $24 \mathrm{LASS}^{*}$ & $18($ Year 2) \\
\hline Average & 22.75 & & & $10($ Year 3) \\
\hline Range & 23 & & & \\
\hline SD & 4.63 & 0.50 & 0.49 & 0.75 \\
\hline Total & 59 & 60 & 59 & 60 \\
\hline
\end{tabular}

NOTE: NSE* = Natural Science \& Engineering, LASS* = Liberal Arts \& Social Science; ** means including both undergraduates and graduates.

In sample 1 (the mainland Chinese students) (See Table 2), the average age was $20.45(S D=1.17)$, the youngest was 18 years and the eldest was 23 years (See Table 1$), 45 \%(n=18)$ of whom were women, and $55 \%(n=22)$ of whom were men. In addition, $72.5 \%(n=29)$ of the respondents' majors in the sample were Natural Science \& Engineering $(S D=0.45)$, and $27.5 \% \quad(n=11)$ of whom were Liberal Arts \& Social Science; $42.5 \%(n=17)$ were first-year undergraduates, $32.5 \%(n=13)$ were second-year undergraduates, and 25\% $(n=10)$ were third-year undergraduates $(S D=1.17)$, and the standard deviation was 0.81 . In sample $1,57.5 \%(n=23)$ of whom were the only child in their families with one missing $(S D=0.49)$, and $40 \%(n=16)$ were not.

Table2. Descriptive Data for Sample 1 Background Information

\begin{tabular}{|l|l|l|l|l|}
\hline & \multicolumn{1}{|c|}{ Age } & \multicolumn{1}{c|}{ Gender } & \multicolumn{1}{c|}{ Major } & Year in this degree \\
\hline Youngest & 18 & $22(\mathrm{M})$ & $29 \mathrm{NSE}^{*}$ & $17($ Year 1)** \\
\hline Eldest & 23 & $18(\mathrm{~F})$ & $11 \mathrm{LASS}^{*}$ & $13($ Year 2) \\
\hline Average & 20.45 & & & 10 (Year 3) \\
\hline Range & 5 & & & \\
\hline SD & 1.17 & 0.50 & 0.45 & 0.81 \\
\hline Total & 40 & 40 & 40 & 40 \\
\hline
\end{tabular}

NOTE: NSE $^{*}=$ Natural Science \& Engineering, LASS $*$ Liberal Arts \& Social Science; $* *$ means undergraduates.

In sample 2 (Chinese sojourners) (See Table 3), the average age was 27.58 with one missing $(S D=$ 5.46), the youngest was 21 years and the eldest was 41 years (See Table 3), 60\% $(n=12)$ of whom were women, and $40 \%(n=8)$ of whom were men $(S D=0.50)$. In addition, $30 \%(n=6)$ of the respondents' majors in the sample were Natural Science \& Engineering (one missing), and $65 \% \quad(n=$ 13) of whom were Liberal Arts \& Social Science $(S D=0.47) ; 75 \%(n=15)$ were first-year graduates, $25 \%(n=5)$ were second-year graduates, and the standard deviation was 0.44 . In sample 2, $35 \%(n=7)$ of whom were the only child in their families $(S D=0.48)$, and $65 \%(n=13)$ were not. 
Table3. Descriptive Data for Sample 2 Background Information

\begin{tabular}{|l|l|l|l|l|}
\hline & \multicolumn{1}{|c|}{ Age } & \multicolumn{1}{c|}{ Gender } & \multicolumn{1}{c|}{ Major } & Year in this degree \\
\hline Youngest & 21 & $8(\mathrm{M})$ & $6 \mathrm{NSE}^{*}$ & $15($ Year 1)** \\
\hline Eldest & 41 & $12(\mathrm{~F})$ & $13 \mathrm{LASS} *$ & $5($ Year 2)*** \\
\hline Average & 27.58 & & & \\
\hline Range & 20 & & & \\
\hline SD & 5.46 & 0.50 & 0.47 & 0.44 \\
\hline Total & 19 & 20 & 19 & 20 \\
\hline
\end{tabular}

NOTE: NSE* = Natural Science \& Engineering, LASS* = Liberal Arts \& Social Science; ** means graduates.

\subsection{Materials and Procedures}

Due to the geographical hurdle, individual interviews were not considered in this research, although such a qualitative research survey is of great importance for sociologists and social anthropologists who want to find out how different cultures (or sub-cultures) work (Gillham, 2000), and especially it can help to complement and cross-validate the data gathered from the questionnaire survey. Based on Gillham's (2000) summarized eight advantages of questionnaires, the researcher decided, therefore, that the questionnaire seemed to represent an appropriate tool for the present survey, and that students might be reasonably assumed to have a personal interest in the subject, thus provoking a worthwhile response.

Babbie (1995) observes that questionnaires need to be carefully developed, tested and debugged before they are administered on a larger scale. Initially, therefore, a pilot study was carried out among 10 mainland Chinese students, who were not subsequently included in the survey. This was principally to determine the length of time taken to complete the questionnaire and to reveal any difficulties or ambiguities in question wording. As a result, some instructions were modified for clearer interpretation by respondents, some statements were re-phrased and some difficult terms in some statements were translated into Chinese so that they could be more easily understood.

To answer the research questions, the research survey was conducted by means of a structured selfcompletion questionnaire with closed questions to the data expected. The questionnaires were either handed to the Chinese sojourners individually, or distributed amongst their classmates in Cardiff University. The questionnaire was distributed to mainland Chinese students by e-mailing it to the researcher's dear colleague, who was entrusted to print 40 hard copies, and gathered the respondents together to complete the questionnaires in a lecture room. Then, the completed questionnaires were sent back to the researcher by e-mail.

The items in the questionnaire were developed to measure the constellation of thoughts, feelings, attitudes, beliefs, and actions (behaviours) composing independent and interdependent self-construals as described previously. 24 items were culled from Singelis' 45 SCS items (1994). In addition, the questionnaire included 5 items drawn from the scale used by McCrosskey (1982); 3 items drawn from the scale used by Duran (1983); 1 item from the scale used by Wiemann (1977), and 3 items from Putnam and Wilson (1982). Some items were rewritten to make them more suitable for a student sample. All together, 48 items were included in the final Self-Construal on Communication Competence.

The presentation format for the 48 SCCCS items in the questionnaire was identical to that in the Singelis' SCS. Respondents were asked to indicate their agreement with the items in a 7-point Likerttype format. It took respondents between 10 and 15 minutes to complete the questionnaire. The questionnaire was composed of: Background Information, Style and Feelings about Communication, Interdependent Items, Communication Behaviour, and Independent Items, which in fact are three separate scales preferred. The order of the overall items was purposely counter-balanced, so that this would not bore the respondents.

\section{ANALYSIS AND RESULTS}

In this section, the results and data analysis are presented in several steps. To analyze the data collected, some specific statistical techniques were employed. With the help of SPSS for windows, Cronbach's alpha reliability was employed to measure the reliabilities of the three subscales in the questionnaire. In addition, bivariate analysis, the independent and related $t$ tests, were used to reduce 
and summarize data, and find out the possible significant differences and correlations between variables.

When the data were being entered, it was found that item 28 was in accidental duplication of item 27. Therefore, item 32 was dropped in this final data analysis. Thus, in fact, only 48 items were included in total.

\subsection{Reliability of Items on the Three Scales}

According to Bryman \& Cramer (1997: 63), the reliability of a measure refers to its consistency, which is often taken to purport two separate aspects - external and internal reliability. In this section, internal reliabilities of the three subscales were tested by computing Cronbach's alphas in this study.

Cronbach's alpha for Communication Competence Scale was $0.81(N=60)$, which was judged adequate, at the 0.8 criterion (Bryman \& Cramer, 1997). This subscale was in fact internally reliable since the alpha coefficients was 0.81 , which was regarded as internally reliable for the purpose of this research. Therefore, Cronbach's alpha reliability was acceptable for this subscale. All items included on this scale that emerged clearly reflect individuals' communication beliefs, feelings and behavior.

And Cronbach's alpha for Interdependence Scale was $0.72(N=60)$, and one item had been deleted, since it did not belong to the group. The finding was judged adequate, though this was just short of the 0.8 criterion (Bryman \& Cramer, 1997). This subscale was in fact internally reliable since the alpha coefficients was 0.72 , which was regarded as internally reliable for the purpose of this research.

Finally, Cronbach's alpha for Independence Scale was $0.68(N=60)$, which was judged moderate and adequate, though this was just short of the 0.8 criterion (Bryman \& Cramer, 1997). This subscale was in fact internally reliable since the alpha coefficients was 0.68 , which was regarded as internally reliable for the purpose of this research. Therefore, Cronbach's alpha reliability was acceptable for this dimension of self construal, which is consistent with Markus and Kitayama's (1991) conception of independent self construal.

\subsection{Relationship between Perceptions of Interdependent vs. Independent Self Construals and Communication Competence}

To investigate Research Question 1 (What is the relationship between perceptions of oneself as interdependent vs. independent self construals and perceptions of communication competence?), the Independent Samples $t$-test and bivariate analysis were employed to find out their possible differences and their relationships respectively for this research purpose.

To find out the possible differences and relationships between interdependence vs. independence and communication competence, the Independent Samples $t$-test and bivariate analysis were employed. Before the two measures were conducted, all the reliable variables on the three scales drawn from Cronbach's alpha reliability were computed into new variables and reorganized. For example, the variables on the interdependent scale were computed into a new variable 'newcom', and the variables on the communication competence scale, were computed into a new variable 'newinter', and the variables on the independent scale were computed into 'newinde'.

\subsubsection{Interdependence versus Communication Competence}

Firstly, the Independent Samples $t$-test was conducted between subjects, that is, the two samples, sample 1: the mainland Chinese students, and sample 2: the Chinese sojourners. The $t$-test indicated that there was no significant difference between the mainland Chinese students and the Chinese sojourners self construals on interdependence scale $(t=0.589, d f=57, p=0.55>0.05)$ and communication competence scale $(t=0.854, d f=56, p=0.39>0.05)$. An examination of means indicated that the two samples scored very close on the items loaded on interdependence (S1: $M=$ 5.16, $N=40 ; \mathrm{S} 2: M=5.04, N=19$ with one data missing) and competence (S1: $M=3.53, \mathrm{~N}=38$ with two data missing; S2: $M=3.31, N=20$ ) scales.

From the correlations matrix, we learned that there was no significant correlations between the two dimensions (recoded as newinter and newcom). The findings revealed that interdependent self construals did not correlate with communication competence self construals, for instance, $r=0.038, N$ $=59, \mathrm{p}=0.77>0.05$. The findings would be fully discussed in the following chapter. 


\subsubsection{Independence versus Communication Competence}

Here again, the Independent Samples $t$-test (See Appendix 6 ) indicated that there were no significant differences between the mainland Chinese students' and the Chinese sojourners' self construals on independence dimension $(t=0.824, d f=58, p=0.41>0.05)$ and communication competence dimension $(t=0.854, d f=56, p=0.39>0.05)$. An examination of means indicated that the two samples scored very close on the items loaded on independence (S1: $M=4.60, N=40 ; \mathrm{S} 2: M=4.41$, $N=20$ ) and competence (S1: $M=3.53, N=38$ with two data missing; S2: $M=3.31, N=20$ ) scales.

From the Correlations obtained from bivariate correlation, we learned that there was a moderate correlation between the two dimensions (recoded as newinde and newcom). The findings revealed that independent self construals negatively correlated with communication competence self construals, for instance, $r=-0.346, N=60, \mathrm{p}=0.008<0.01$. The findings would be fully discussed in the following chapter as well.

\subsection{Self Perceptions of Communication Competence}

Research Questions 2 and 3 asked whether a Western cultural context would influence the Chinese sojourners' perceptions of communication competence, and if their perceptions would differ from the mainland Chinese students. This was assessed by calculating the differences between the two samples' perceptions of the communication competence dimension (which has been computed into newcom), and thus the independent $t$-test was run.

Here the respondents from mainland China were coded as sample 1, and the Chinese sojourners were coded as sample 2. The findings indicated that there was no significant difference between the two samples' self perceptions of the competence $(t=0.854, d f=56, p=0.397>0.05)$. Table 4 summarized the results of means obtained from each of the respondents' reports, which showed that the two samples scored very close on the competence dimension ( $\mathrm{S} 1$ : lowest: $\mathrm{M}=2.10$, highest: $\mathrm{M}=$ 4.60; S2: lowest: $M=2.20$, highest: $M=4.10$ ). In other words, the Chinese sojourners' perceptions of communication competence did not differ from the mainland Chinese students. Therefore, we may infer that a Western cultural context did not clearly influence the Chinese sojourners' perceptions of communication competence. This would be discussed in detail in the following section.

Table4. Independent t-test (average means): Self perceptions of Communication Competence

\begin{tabular}{|l|l|l|l|l|}
\hline \multicolumn{1}{|c|}{ Item } & \multicolumn{1}{c|}{ Sample 1 } & \multicolumn{1}{c|}{ Sample 2 } & \multicolumn{1}{c|}{ Mean } \\
\hline tenseq6 & 40 & 3.33 & 20 & 3.40 \\
\hline nervousq7 & 40 & 3.66 & 20 & 3.65 \\
\hline dislike discussionq8 & 40 & 3.15 & 20 & 2.85 \\
\hline feel vervous9 & 40 & 3.35 & 20 & 2.95 \\
\hline afraidq10 & 40 & 3.23 & 20 & 2.95 \\
\hline hesitateq11 & 40 & 3.68 & 20 & 3.35 \\
\hline not like to shareq12 & 40 & 2.88 & 20 & 2.20 \\
\hline personal relationsq17 & 40 & 2.10 & 20 & 2.35 \\
\hline seem differentq30 & 40 & 3.85 & 20 & 3.85 \\
\hline shy awayq31 & 40 & 4.60 & 20 & 4.45 \\
\hline keep quietq33 & 40 & 3.60 & 20 & 3.65 \\
\hline avoidq34 & 30 & 3.45 & 20 & 2.95 \\
\hline
\end{tabular}

\section{DISCUSSION AND CONCLUSION}

In answering Research Question 1, the findings of the two Independent Samples $t$-tests suggest that there are no significant differences between the mainland Chinese students' and the Chinese sojourners' self construals on both interdependence dimension and competence dimension, independence dimension and competence dimension.

The first Independent Samples $t$-test shows that there are no significant differences between the two samples' self perceptions of interdependence dimension and communication competence dimension. Moreover, the bivariate correlation indicates that there is no significant correlation between the two dimensions. In other words, interdependent self construals do not correlate with communication competence self construals. The findings suggest that the Chinese traditional values (interdependence dimension) do not affect the Chinese students' communication competence. For example, the two samples score very high on item 19 on interdependence dimension ("It is important for me to maintain 
harmony within my group"): S1: $M=6.38, N=40 ; \mathrm{S} 2: M=6.10, N=20$. Similarly, they, too, score high on item 31 on communication competence dimension ("I shy away from topics that are sources of disputes"): S1: $M=4.60, N=40 ; \mathrm{S} 2: M=4.45, \mathrm{~N}=20$. This supports Gudykunst et al's (1988), and Gudykunst's (1997) argument that the culture in which individuals are socialized influences the way they communicate. It also supports Chu's (1988) position that to maintain harmony, Chinese always try to avoid dissenting opinions carefully, and conversations are not only carefully worded but also calculated for this purpose. As discussion of conflicts in public may be interpreted as 'losing face,' dissenting views are usually suppressed or reserved for more private occasions.

In addition, the findings have refuted Klopf's (1992) argument that many Asians, less talkative and assertive in interpersonal situations than their Western counterparts, have been labeled as communicatively apprehensive (cited in Miyahara, 1998). But the results support Markus' and Kitayama's (1991) proposition that non-Western peoples hold an interdependent image of self stressing connectedness, social context, and relationships (solidarity with others, Gudykunst, et al., 1996), and too, support conceptualization of East Asians' emphasis on interpersonal relationships (e.g. Yum,1988; Rita, 1998).

An examination of means reported shows that the Chinese students score high on interdependence, and score low on competence scale (because most of the items on competence scale are negatively worded). The findings indicate that the Chinese students' interdependence is highly developed, and when the competence items are reversed scoring them, the Chinese students also score high on communication competence, they believe they are competent. We may conclude that culture teaches one how to think, conditions one how to feel, and instructs one how to act, especially how to interact with others.

Another Independent Samples $t$-test also shows that there is no significant difference between the mainland Chinese students' and the Chinese sojourners' self construals on independence dimension and communication competence dimension. Although this $t$-test shows no significant difference between the two samples' self perceptions of the two dimensions (independence and competence) (which may be due to the fact that most of the items on competence scale are negatively worded), the bivariate analysis indicates that there is a moderate correlation between the two dimensions. The findings reveal that independent self construals negatively correlate with communication competence self construals.

An examination of means reported shows that the Chinese students score relatively high on independence, and score low on competence scale (because most of the items on competence scale are negatively worded,). The findings indicate that the Chinese students' independence is also well developed, and when the competence items are reversed scoring them, the Chinese students also score high on communication competence, they believe they are competent. This suggests that independence affects the individuals' communication competence. Moreover, the respondents' means clearly reflect the Chinese students being autonomous, unique. The results are consistent with Singelis' (1994) argument that East Asian students have both well developed interdependent selfconstruals and independent self-construals.

The findings for research questions 2 and 3 show no significant differences between the two samples' perceptions of the communication competence dimension based on their mean scores. We may infer that a Western cultural context did not clearly influence the Chinese sojourners' perceptions of communication competence (e.g. their communication styles and beliefs). But this may have aroused a new issue, that is, most of the Chinese sojourners may be facing the difficulty adapting themselves to new cultural environment, which is in fact central to the acculturation process (Singelis, 1994). Besides, the period of time they have stayed in Britain, and how often they communicate with the native speakers (their counterparts), are all the important domains that are beyond this study, and need further exploration in the future study.

To conclude, this research has sought to investigate the relationship between communication and culture. It has investigated in what ways the Chinese traditional values (defined as cultural selfconstrual) influence Chinese students' perceptions of communication competence and style. Hopefully, it will help readers to gain an insight into cultural impact on Chinese students' self construals on communication competence in the traditional cultural context and a Western cultural context. 


\section{REFERENCES}

[1] Babbie, E. (1995). The Practice of Social Research. Belmont: Wadsworth Publishing Company.

[2] Beatty, M. J. (1988). Situational and predispositional correlates of public speaking anxiety. Communication Education, Vol. 37, 28-39.

[3] Bond, M. H., \& Hwang, K. K. (1986). The Social Psychology of Chinese People. In Bond, M. H. (Ed.), The Psychology of the Chinese People. Hong Kong, Oxford, New York: OXFORD UNIVERSITY PRESS.

[4] Byram, M. (1997). Teaching and Assessing Intercultural Communicative Competence. Clevedon, Philadelphia, Toronto: MULTILINGUAL MATTERS LTD

[5] Bryman, A., \& Cramer, D. (1997). Quantitative Data Analysis with SPSS for Windows — A guide for social scientists. London and New York: ROUTLEDGE.

[6] Chu, Godwin C. (1988). In Search of an Asian Perspective of Communication Theory. In Dissanayake, Wimal (Ed.), Communication Theory: The Asian Perspective. Asian Mass Communication Research and Information Centre.

[7] Chu, L. L. (1988). Mass Communication Theory: A Chinese Perspective Theory. In Dissanayake, Wimal (Ed.), Communication Theory: The Asian Perspective. Asian Mass Communication Research and Information Centre.

[8] Chua, C. M. (2003). Perceptions of Communication Behaviour in Malaysia Work Contexts: Supervisos versus Trainees. (Thesis submitted for the degree of Ph.D). University of Wales.

[9] Dawson, R. (1981). Confucius. Oxford, New York and Toronto: Oxford University Press.

[10] Duran, R. L. (1983). Communicative adaptability: A measure of social communicative competence. Communication Quarterly, Vol. 31, 320-326.

[11] Fairbank, J. K., \& Reischauer, E. O. (1979). China :Tradition and Transformation. Sydney (etc.) : George Allen \& Unwin

[12] Fung, Y. L. (1952). A History of Chinese Philosophy. (Second Edition). Vol. I. Princeton: Princeton University Press.

[13] Gilbert, G. N. (1993). Researching Social Life. London: SAGE.

[14] Gillham, B. (2000). Developing a Questionnaire. London and New York: Continuum.

[15] Guan, S.J. (1998). The Prospects for Cross-Cultural Communication between China and the West in the $21^{\text {st }}$ Century. In D. R. Heisey \& Wenxiang Gong (Eds.), Communication and Culture: China and the World Entering the $21^{\text {st }}$ Century. Critical Studies Vol. 12. Editions Rodopi B. V., Amsterdam - Atlanta, GA.

[16] Gudykunst, W. B. \& Ting-Toomey, S. (1988). Interpersonal Communication. Newbury Park, London: SAGE Publications

[17] Gudykunst, W. B. (1997). Cultural Variability in Communication: An Introduction. Communication Research. Vol. 24 No. 4, 327-348. Sage Publications, Inc.

[18] Guirdham, M. (1999). Communicating across Cultures. Houndmills, London: MACMILLAN Business.

[19] Guo, B. L. (1997). The Theory of Wu Xing.. http://www.zgxl.net: Chinese Physiological Health Online

[20] Hammer, M.R.(1989). Intercultural Communication Competence. In Asante, M.K. \& Gudykunst, W.B. (eds). Handbook of International and Intercultural Communication. Newbury Park, London, New Delhi: SAGE Publications.

[21] Hewstone, M., Stroe.be, W., Codol, J.-P. \& Stephenson, G. M. (eds) (1988). Introduction to social psychology: a European perspective. Oxford : Basil Blackwell.

[22] Kim, M. S. (1993). Cultural-Based Interactive Constraints in Explaining Intercultural Strategic Competence. In Wiseman, R. L., \& Koester, J. (Eds.), Intercultural Communication Competence. Newbury Park, London, New Delhi: SAGE Publications.

[23] Kim, U., Triandis, H. C., Kagitcibasi, C., Choi, S. C. \& Yoon, G. (1994). Individualism and collectivism : theory, method, and applications. Thousand Oaks, Calif : Sage Publications

[24] Kinnear, P. R., \& Gray, C. D. (2000). SPSS for Windows Made Simple Release 10. East Sussex: Psychology Press Ltd, Publishers.

[25] Kline, P. (1994). An Easy Guide to Factor Analysis. London and New York: ROUTLEDGE.

[26] Lustig, M.W., \& Koester, J. (1999). Intercultural Competence. New York, England, Sydney, Amsterdam: Longman.

[27] McCroskey, J. C. (1982). An introduction to rhetorical communication (4 ${ }^{\text {th }}$ ed.). Englewood Cliffs, NJ: Prentice Hall.

[28] Miyahara, A. (1998). Philosophical Issues in Cross-Cultural Research on Communication Competence between Asians and Westerners. In D. R. Heisey \& Wenxiang Gong (Eds.), Communication and Culture: 
China and the World Entering the $21^{\text {st }}$ Century. Critical Studies Vol. 12. Editions Rodopi B. V., Amsterdam - Atlanta, GA.

[29] Neuliep, J.W. (1997). A Cross-Cultural Comparison of Teacher Immediacy in American and Japanese College Classrooms. In Gudykunst, W.B.(Ed), Communication Research. Vol. 24, No 4. Thousands Oaks, London, New Delhi: Sage Periodicals Press.

[30] Putnam, L. L., \& Wilson, C. E. (1982). Communicative strategies in organizational conflict: Reliability and validity of a measurement scale. Communication Yearbook, Vol. 6, 629-652.

[31] Rita, M. C. Ng. (1998). The Influence of Collectivism-Individualism on Persuasion in Chinese and American Cultures. In D. R. Heisey \& Wenxiang Gong (Eds.), Communication and Culture: China and the World Entering the $21^{\text {st }}$ Century. Critical Studies Vol. 12. Editions Rodopi B. V., Amsterdam - Atlanta, GA.

[32] Sarbaugh, L. E. (1988). A taxonomic approach to intercultural communication. In Kim, Y.Y. \& Gudykunst, W.B. (eds). Theories in Intercultural Communication. Newbury Park, CA: Sage.

[33] Singelis, T. M. (1994). The Measurement of Independent and Interdependent Self-Construals. Personality and Social Psychology Bulletin. Vol. 20 No.5, 580-591.

[34] Singelis, T. M. (2000). Some Thoughts on the Future of Cross-Cultural Social Psychology. Journal of Cross-Cultural Psychology. Vol. 31, 76-91.

[35] Spitzberg, H. H., \& Cupach, W. R. (1984). Interpersonal Communication Competence. Beverly Hills, CA: Sage.

[36] Spitzberg, H. H., \& Cupach, W. R. (1989). Handbook of Interpersonal Competence Research. New York, Berlin, London: Springer-Verlag.

[37] Ting-Toomey, S. (1989). Identity and Interpersonal Bonding. In M. K. Asante \& W. B. Gudykunst (Eds.), Handbook of International and Intercultural Communication (pp. 351-373). Newbury Park, London: SAGE Publications.

[38] Triandis, H. C. (1988). Collectivism vs. individualism: A reconceptualization of a basic concept in crosscultural psychology. In G. K., Verma \& Bagley, C. (Eds.), Cross-cultural studies of personality, attitudes and cognition. London: Macmillan.

[39] Van Ek, J.A. (1986). Objectives for Foreign Language Learning, Vol. 1: Scope. Strasbourg: Council of Europe.

[40] Waley, A. (1938). The Analects of Confucius. New York: Random House.

[41] Wiemann, J.M. (1977). Explication and Test of A Model of Communicative Competence. Human Communication Research. Vol. 3, 195-213.

[42] Yum, J.O. (1988). The impact of Confucianism on interpersonal relationships and communication patterns in East Asia. Communication Monographs, Vol. 55, 374-388.

Citation: Gang Zhou*, Xiaochun Niu. "The Cultural Impact of Chinese Students' Self-Construals on Communication Competence "International Journal on Studies in English Language and Literature (IJSELL), vol 6, no. 9, 2018, pp. 58-67. doi: http://dx.doi.org/10.20431/2347-3134.0609007.

Copyright: (C) 2018 Authors. This is an open-access article distributed under the terms of the Creative Commons Attribution License, which permits unrestricted use, distribution, and reproduction in any medium, provided the original author and source are credited. 